\title{
Correspondence
}

\section{NHS managers and clinical management}

DeAr Sirs

I was very interested to read Anne Farmer's \& Mark Winston's letter (Psychiatric Bulletin, 1992, 16, 567) and would like to clarify a number of issues.

Patients detained in hospital under Part II of the Mental Health Act are legally detained by the managers subject to certain limited exceptions; the managers are empowered to discharge detained patients.

The managers are defined in Section 145 of the Mental Health Act 1983, and in relation to a directly managed unit they are the district health authority responsible for the unit. The DHA is empowered to appoint a sub-committee to undertake this function which frequently is composed of a mixture of health authority members and other persons with an interest in/or experience of mental health issues.

The managers have a range of duties all of which can be devolved to officers, apart from the power to discharge. This can be exercised only by three or more managers in person, none of whom should be an executive member of the authority.

With the exception of Mental Health Review Tribunals (Section 72 and 73 of the Act) the Act is silent about the criteria that should govern the exercise of the power to discharge, although Richard Jones in his Mental Health Act Manual (Sweet \& Maxwell, 3rd edition, 1991, page 67) submits that "those who have a power to discharge should assess the need for the patient's continued detention by considering whether, (1) the patient is still suffering from mental disorder; (2) his disorder continues to be of a nature or degree which makes treatment in a hospital appropriate; and (3) detention in a hospital is still necessary in the interests of his own health or safety or for the protection of others".

If Richard Jones is correct in his submission, it is within that context that the various "rights" (to be discharged, as opposed to being provided with "assured and optimal care") referred to by the authors, have to be considered.

The Mental Health Act Commission has never formally expressed itself in the manner ascribed to it by the authors, that the managers' responsibilities are confined to ensuring "that the legal documentation and procedures have been correct and that consideration of the patient's discharge should remain with the full Mental Health Review Tribunal which includes expert clinical opinion". The main thrust of the Commission's concerns about "managers" and Mental Health Review Tribunals has been to emphasise the importance of the patient fully understanding the difference between the two.

While I appreciate the concerns of the authors about the abilities of some managers' panels adequately to consider possible discharge of a detained patient, I do not think it necessarily follows that a Mental Health Review Tribunal is the exclusive body capable of evaluating the sort of issues referred to in their letter. It is the Commission's experience that managers very rarely discharge patients against the advice of the patient's responsible medical officer, but it has come across a number of cases where managers have very effectively reviewed the clinical reasons given for a patient's continued detention and have appropriately ordered the discharge of the patient from detention. Managers' decisions should be the subject of audit.

I think that the authors are going a little far when they cite the exercise of the managers' power of discharge as another example of the increasing intrusion of NHS managers into areas of clinical responsibility. The fact is that the managers have possessed this power since the passing of the 1959 Mental Health Act. What may have changed is that managers have taken this responsibility more seriously since the 1983 Mental Health Act focused the attention of all those involved in mental health care rather more clearly on the rights of patients as set out in legislation. The Code of Practice (Chapter 24) contains extensive guidance for managers, in relation to their responsibilities to review detention, but I agree that it does not specifically address the criteria which managers should adopt when considering discharge. It is interesting to note, however, that one of the criticisms (entirely justified, in my view) made by the authors of the way in which the specific case referred to in their letter was handled, was that the managers had had no communication with the patient's nearest relatives. The Code (at Chapter 22.4 and 22.5e) emphasises the importance of the managers obtaining the views of the patient's nearest relative and all most concerned relatives.

Mental Health Act Commission

WILliAM BingleY Chief Executive

Maid Marian House

56 Houndsgate

Nottingham NG1 6BG 